von hoher innerer Reibung, in welchem ein erheblicher Anteil des Wassers bereits als Hydratationswasser anzunehmen ist. Alle die genannten Ursachen machen es vor Anstellung weiterer Versuche unmöglich, über den Veriauf der $\alpha$-Werte in unserm speziellen Fall theoretische Betrachtungen zu pflegen.

Mit Hilfe des $\boldsymbol{a}$-Mittelwertes haben wir die Viskosität der Suspensionen nach der Formel $\eta_{\mathrm{s}}=\frac{\eta}{1-\alpha \mathrm{K}}$ zurückberechnet. Die erhaltenen Zahlen sind in der Tabelle II verzeichnet und in Pigur 1 durch kleine Dreieckchen kenntlich gemacht. Mit Ausnahme der letzten Messung ist die Uebereinstimmung zwischen Beobachtung und Berechnung eine sehr befriedigende. Besonders der Kurvenbeginn wird sehr gut durch die $\mathrm{He}$ B 'sche Gleichung dargestellt, aber selbst bei den höheren Konzentrationen ist die Uebereinstimmung noch eine gute. Lediglich der letzte Wert făllt gänzlich heraus. Bedenken wir, daB die 'He' $B$ 'sche Beziehung, wie der Autor selbst betont, nur unter bestimmten Voraussetzungen gilt und schon mit Rücksicht darauf, $\mathrm{daB} \alpha$ sich mit der Konzentration ändert, nicht einen allzu großen Konzentrationsbereich umfassen kann, so können wir um so zufriedener sein, dab die genannte Beziehung auch für die Viskositäts - Konzentrationsfunktion derart kom- pliziert zusammengesetzter Systeme, wie wir sie in Händen hatten, befriedigend zutrifft.

\section{Zusammenfassung:}

1. Die Viskositäts - Konzentrationsfunktion kompliziert zusammengesetzter polydisperser Sy* steme (Mehl-Wassermischungen) läBt sich durch die empirisch ermittelte Gleichung

$$
\eta_{\mathrm{s}}=\eta_{\mathrm{o}}\left(1+\mathbf{k} \cdot \mathbf{f}+\mathrm{k}_{1} \cdot \mathbf{f}^{\mathrm{ki}}\right)
$$

darstellen, worin $\eta_{\mathrm{s}}$ die Viskositäit der Suspension, $\eta_{0}$ die des Wassers $(=1)$, f das Volumenverhältnis von disperser Phase zu Gesain volumen, $k, k_{1}$ und $n$ Konstanten bedeuten. Die Gleichung ist formal und genetisch der von Wo. Ostwald und $K$. Mündler für den osmotischen Druck von Dispersoiden gefundenen ähnlich.

2. Fernerhin wird die Viskositäts - Konzentrationsfunktion der genannten Systeme in befriedigender Weise durch die von W. R: HeB theoretisch abgeleitete Beziehung

$$
\eta_{\mathrm{s}}=\frac{\eta}{1-\alpha \mathrm{K}}
$$

dargestellt, wobei $\eta_{\mathrm{s}}$ die Viskosität der Suspension, $\eta$ die des Dispersionsmittels, $K$ das in der Volumeneinheit enthaltene Volumen an disperser Phase und $\alpha$ den Zusatzfaktor, der zum funktionellen Volumen führt, darstellen.

Technische Hochschule, Mitnchen.

\title{
Kolloidchemische Wirkungen der Salze seltener Erden und ihre Beziehungen zu den Flockungsreaktionen der Antikörper.
}

\author{
Von R. Doerr.
}

(Eingegangen ain 20. Algust 1930.)

(Aus dem hygienischen Institut der Universität Basel. Vorsteher: Prof. R. Doerr.)

Menschenserum und Menscrietintiserum vom Kaninchen liefern ein Reaktionsgemisch, welches bei einem genügenden Gehalt an Elektrolyten ( $\mathrm{NaCl}$ ) einen Teil seiner im Solzustand befindlichen artspezifischen Globuline als Gel, d. b. in Form eines lockeren, weißlichen Niederschlages abscheidet. Vermöge seiner Zusammensetzung aus Globulinen ist dieser Niederschlag in destilliertem Wasser unlöslich; er löst sich aber auch nicht in einprozentigem $\mathrm{Na} \mathrm{Cl}$, ganz im Sinne der herrschenden Auffassung, nach welcher es gerade-der Elektrolyt ist, welcher die Ausflockung der Eiweißkolloide bedingt, sobald diese infolge der vorausgegangenen Bindung zwischen Präzipitinogen und Präzipitin ihre Stabilität eingebübt und sich in ihrer Empfindlichkeit gegen fällende Salze dem Verhalten hydrophober Kolloide angenähert haben. In $\frac{\mathrm{n}}{10} \mathrm{NaOH}$ lösen sich dagegen spezifische Niederschläge restlos und völlig klar.

Zur Erzielung spezifischer Präzipitate ist bekanntlich die Einhaltung bestimmter quantitativer Verbältnisse zwischen den beiden Reaktionskomponenten (präzipitinogenes Eiweiß und präzipitierendes Serum) erforderlich, und $z$ war in einem doppelten Belange.

Zunächst hindert ein Ueberschub von Präzipitinogen die Präzipitation ( $M$ i chaellis und Oppenheimer); daB das artspezifische Eiweib hierbei nicht als einfaches Schutzkolloid, sondern tatsächlich als Antigen wirkt, läßt sich eben durch die Spezifität dieser Hemmung leicht beweisen. Nur ein UeberschuB an Menschen- 
serum, stort die Plockung eines Reaktionsgemisches von Menschenserum und korrespondierendem .Pıäzipitin, nicht aber ein äquivalenter Zusatz von Pferdeserum bei reaktionsfähiger Menge von MenscheneiweiB. Nach Landste in er's letzten Arbeiten zu urteilen kommt die Antigenfunktion und ihr wesentlichstes Attribut, die Spezifität, im geschilderten Hemmungsphänomen sogar reiner zum Ausdruck, als in der Bildung der spezifischen Niederschläge; weil sie im ersten Falle von der Bedingung der Verkettung mit einem kolloiden Eiweißräger anscheinend weitgehenu abgelöst-werden kann. Lảbt man den Antigeniaberschub auf das bereits gebildete, aus dem Reaktionsgemisch isolierte und mit einprozentigem $\mathrm{NaCl}$ auf der Zentrifuge gewaschene Präzipitat einwirken, so kann das letztere (speziell bei $37^{\circ} \mathrm{C}$, oft aber auch schon bei Zimmertemperatur) wieder in Losung gehen, d. h. in ein Globulinsol rückverwandelt werden; doch vollzieht sich dieser Prozeb nur, wenn die Niederschläge eine bestimmte $\mathrm{Zu}$ sammensetzung haben, und erfordert weit gröBere Anigenmengen oder richtiger höhere Antigenkonzentrationen als die Hemmung des Präzipitationsvorganges. Die Abhängigkeit der Reversibilität des Gels durch Antigenkontakt von den quantitativen Bedingungen seiner Entstehung lehrt folgendes Beispiel:

\section{Versuch.}

a) Ein Niederschlag aus $10 \mathrm{ccm} 0,85$ prozentigem $\mathrm{NaCl}+0,02 \mathrm{ccm}$ Menschenserum $+1,0 \mathrm{ccm}$ Antimenschenserum von Kaninchen-7. wird abzentrifugiert, gewasehen, in 1,5 ccm 0,85 prozentigem $\mathrm{NaCl}$ aufgeschwemmi und je ein. Drittel versetzt:

1. mit $1 \mathrm{ccm}$ Pfèrdeserum : bleibt trube, setzt allmählich wieđer einen massigen Niederschlag $a b$.

2. tmit 5 ccm Pferdeserum: verhàlt sich wie 1 .

3. mit $1 \mathrm{ccm}$ Menschenserum; $2 \mathrm{e} / \mathrm{gt}$ s of ort deatliche Aufhellung, wird nach mebrstiudigem Stehen ganz klar.

b) Ein zweiter Niederschlag aus $50 \mathrm{ccm} \mathrm{NaCl}$ $+0,2 \mathrm{ccm}$ desselben Menschenserums $+4 \mathrm{ccm}$ des gleichen Präzipitins wird abzentrifuglert, gewaschen, in $12 \mathrm{~cm} \mathrm{NaCl}$ aufgeschwemmt und je $1 / \mathrm{zz}$ versetzt:

1. mit $2,5 \mathrm{~cm} \mathrm{NaCl}$ : bleibt trïbe, scheidet ein Prazipitat $a b$,

2. mit $7,0 \mathrm{cem} \mathrm{NaCl}$ : wie 1 ,

3. , 2,5, Pferdeserum: wie 1 ,

4. "7,0 ", 1 ,

5. " 1,5, Menschenserun: wie 1 ,

$6 ., 2,5, \quad, \quad$,

7. "1,9" Antimenschenscrum von Kaninchen 7 : wie 1 .

im Prinzip kann wohl kein $Z$ weifel besteben, dab die Hemmung der Niederschlagsbildung and die nachirägliche Lösung fertiger Präzipitate auf Identischen Ursachen bermhen muissen, wotür ja abgesehen von anderen Momenten auch die Tatsache spricht, dab es sich in beiden Fälien um spezifische Antigenwirkungen handelt. Wo sich daher die Hemmung beobachten läßt, sollte auch die Lösung durch Antigen möglich sein; gelingt die letztere trotz Variierung der quantitativen Beziehungen der Reaktionskomponenten nicht, so kann der Grund entweder in einer sekundären Verfestigung (Hysteresis) : des Präzipitates oder darin liegen, daB die zur Lösung des Niederschlages erforderliche Antigenkonzentration bei gegebenem Reaktionsvolum nicht erreicht werden, kann.

Das umgekehrt ein Ueberschub an präzipitierendem Serum die Präzipitation zu verhindern vermag bei einer an und für. sich reaktionsfähigen Antigenkonzentration, ist bei der Relativität aller zwischen Antigenen und ihren kolloiden Antagonisten auftretenden Wirkungen a priori anzunehmen und auch direkt konstatiert worden. Atlerdings bekommt man diesen Fall bei den üblichen Versuchsanordnungen viel seltener zu Gesicht als die Hemrnung durch AntigentiberschuB und daran ist die zweile, meines Erachtens bisher noci immer zu wenig beachtete quantitative Voraussetzung der Niederschlagsbildung in Immunkolloiden schuld.

Ermittelt man nämlich ein für die Entstehung des Niederschlages optimales Verhältnis von Präzipitinogen und Präzipitin und verringert man nun unter Konstanthaltung des einen Faktors den anderen, so wird man gewahr, dab die Antigenkonzentrationen auberordentlich herabgesetzt werden können, während ein Versuch einer Reduktion des präzipitierenderi Serunts alsbald ein Ausbleiben der Präzipitation nach sich zieht: Beträgt z. B. das Reaktionsvolum $1,0 \mathrm{ccm}$, so kann man unter Umständen noch mit 0,0001 ccm Antigen (etwä mit Menschenserum) einen mächtigen Niederschlag erzielen, wenn genügend Antiserunt vorhanden ist; verringert man aber die absolute Menge und damit die Konzentration des letzteren, so wird die Masse des Niederschlages von 0,1 ccm Antiserum an rasch abfallęn und die Ausflockung schon in den nächsten Verdünnungen sistieren, auch wenn das Quantum EiweiBantigen an sich betrachtet öllig ausreicbend wäre.

Die Difierenz zwischen den für die Entstehung eines Niederschlages notwendigen Mengen von Eiwcibantigen einerseits und von Antiserum andererseits gilt fïr die ganze qantitative Reaktionsbreite der beiden Faktoren, ist somit nisht nur in Porn der Mínima erkennbar, sondern in Berejche der Optima und Maxima ebenso 
deutlich ausgeprägt; die Differenz der Maxima z. B. änbert sich wie bereits erwähnt dadurch, dab eine Hemmung der Präzipitation durch AntigenuiberschuB weit leichter und früher cintritt, als durch Steigerung der relativen Konzentration des Antiserums.

Das Studium der Minima wird aber insoferne ergebnisreich, als es $z \mathfrak{u}$ einer. wenn auch nur einseitig bestimmten; so doch sehr wichtigen Aussage über den Anteil führt, mit welchem die beiden Reaktionskomponenten in die Masse des Niederschlages eingehen: LäBt man nämlich minimale Dosen Eiweißantigen mit ausreichenden Mengen präzipitierenden Antiserums abreagieren, so erzielt man Niederschläge von solchem Volumen, daB der blobe Augenschein ihre ausschliebliche Entstehung aus ausgeflocktem Antigeneiweib als eine Unmöglichkeit erkennen läbt; es mub also auch das Autiserum partizipieren, und zwar in hohem Grade. Diese schon von $E$. P. Pick, Leblanc, Linossier und Lemo ine, Camus 4 . a. angebahnte Erkenntnis konnte in zwingender Art bewiesen werden, als man die volumetrisclie Abschätzung der antigenen EiweiBlosungen sowohl als auch der spezifischen Präzipitate durch die Bestimmung der Trockengewichte ersetzte. Auf diesem Wege zeigte Moll 1903, daf das Gewicht des Niederschlages jenes des zur Reaktion verwendeten EiweiBantigens um das zehnfache aberireffen kann, daß somit neun Zehntel desPräzipitates aus dem Antiserum herrühren müssen; 1908 erzielten Welsh und Chapman mit $1 \mathrm{mg}$ Eieralbur min ein spezifisches Präzipitat, welches $26 \mathrm{mg}$ weg und 1909 steigerten Cal mette und Mas sol bei Verwendung von Schlangengift und präzipitierenden Antiserum dieses Verhältnis auf $1: 35$.

Ich habe dann 1911 mit Moldavan die Provenienz der Hauptmasse der Niederschläge aus den Eiweib des Immunserums durch die inzwischen in die Technik eingebürgerten anaphylaktischen Reaktionen bestätigt. Wir stellten Präzipitate aus Rinderserum und Antirinderserum vom Karinchen her und konuten mit den mehrfach gewaschenen Präzipitaten Meerschweinchen gegen Kanincheneiweiß sensibilisieren, also gegen das artspezffische Globulin des Immunserums, während die Sensibilisierung gegen das Präzipitinogen, nämlich gegen Rindereiweib, bei Einhaltung bestimmter quanilativer Bedingungen mit keinen Teil des Reaktionsgemisches gelang.

Es ist also schon seit ziemlich langer Zeit bekannt, daß , dic Auffassung rom Inmunserum als präzipitierender und vom Autigen als präzipitabler Substanz" nicht dem effektiven Reak- tionsgeschehen entspricht; die dahin abzielenden Ergebnisse der interferometrischen Analyse des Präzipitationsphänomens durch $\mathrm{P}$. Hirsch und $K$. Langenstra $B$ haben gelehrt, daB auch die Auwendung empfindlicher und exakter optischer Methoden an diesem wissenschaftlichen Tatbestand nichts ändert, der ja Ursache war, warun man den Ausdruck präzipitable Substanz tür das Antigen fallen lie $B$ und ganz allgemeir durch den Terminus: "Präzipitizogen" ersetzte. Die Bezeichnung "präzipitable Substanz" würde. win J. Bordet richtig bemerkt, viel eher auf das präzipitierende Antiserum passen, für welches man indes vorläufig den Namen "Präzipitin" beibehält, obzwar es derzeit sehr fraglich ist; ob die damit vindizierte aktive, gegen das Antigen gerichtete Rolle den Eiweibkolloiden der Immunsera tatsächlich zukommt (vgl. hierzu Langenstrab).

Das auffallende Ueberwiegen des Antikörpers bzw. des Immunserums über das Eiweibantigen charakterisiert auch noch eine zweite Reaktion, die Anaphylaxie. Wählt man, um die Mengen des reagierenden Antiserums genau abstufen za können, die passiv anaphylakitische Versuchsanordnung, und variiert nun, genau wie das soeben für die Präzipitation beschrieben wurde, einerseits die Dosen des passiv präparierenden AntieiweiBserums von Kaninchen, andererseits die Quantitäten des intravenös injizierten schockauslosenden Antigens; so erbält man ein getreues Spiegelbild der bei der Nieder. schlagsbildung in vitro $\mathbf{z u}$ beobachtenden Verhältnisse: $D$ oerr ind $R u B$ haben auf diese engen quantitativen Beziehungen zwischen Anapliylaxie und Präzipitation zuerst hingewiesen und ich habe auf dieses Argument gestützt die anaphyiaktischen Vorgänge ats eine Globulinflockung, als eine Präzipitation in vivo bezeichnet (vgl. Doerr und Moldovan), ein Standpunkt, den ich auch heute noch unverändert einnekme.

Das der Präzipitation und der Anaphylaxie gemeinsame Moment liegt wohl darin, daß in beiden. Fălleu das Eiweibantigen im lösungsartigen Zustand. als homogenes Eiweibsol in Reaktion tritt. Hat das Antigen die Form einer wăsserigen Suspension, einer Aufschwemmung korpuskulärer Elemente von mikroskopischen Dimensionen (Bakterien, Protozoëin, Erythro. zyten usw,), dann andert sich bas quantitative Verhalten des Antiserums: es bewirkt die Reaktion (Agglutination, Cytolyse) schon in seht geringen Konzentrationen $(1: 1000, j a 1: 100000)$. Ein Ueberschub von Immunserum 1 1:10 bis 
1:50 oder mehr) würde die Ausflockung der Zellsuspension sogar stören, ein Ereignis, welches als "untere Hemmungszone" zu den alltäglichen Laboratoriumserfahrungen gehört. Dieser Gegensatz zwischen Agglutination und Präzipitation ist nicht ohne weiteres verständlich und meines Erachtens auch bis jetzt noch nicht befriedigend erklärt. Einerseits sieht man sich gegenwärtig wohl allgemein genötigt, beide Reaktionen als wesensgleiche Prozesse, als Elektrolytflockungen des Komplexes EiweiBantigenEiweißantikörper zu betrachten; die Entdeckung der Bakterienpräzipitine durch R. Kra u s hat den ersten Ansto B zu einer solchen einheitlichen Auffassung von Agglutination und Präzipitation gegeben ( $\mathrm{P}$ alta uf) und die Fortschritte der Kolloidchemie, speziell die Arbeiten über die Rolle der Salze bei beiden Reaktionen (Bordet, Joos u. A.) haben die unitarische Hypothese ziemlich sicher fundiert. Der Unterschied würde - und diese Darstellung gibt $z$. B. neuerdings Bordet - nur darin liegen, daB die ausgeflockten Elemente bei der Agglutination relativ sehr groß, bei der Präzipitation dagegen auBerordentlich klein sind, also in der enormen Differenz des Dispersitätsgrades der ausfällbaren Partikel des Eiweifantigens. Dafür scheint zu sprechen, daB bei Ueberführung des Bakterieneiweißes in Lösung sofort die quantitativen Gesetze der Prăzipitation an Sielle jener der Agglutination treten, dab also zur Flockung wieder grobe Mengen Immunserum erforderlich werden. Es braucht aber kaum auseinandergesetzt zu werden, dab diese Präzisierung des Sachverhaltes den Kernpunkt des Unterschiedes zwischen den beiden Reaktionen nicht berührt; sie setzt sich vielmehr mit der Beobachtung in Widerspruch, indem sie das EiweiBantigen auch bei der Präzipitation als die präzipitable, als die ausfällbare Substanz hinstellt, was nach früheren Ausführungen nicht zutrifft, und sie erklärt nicht, warum der für die Präzipitation notwendige relative UeberschuB des Immunserums die Agglutination verhindert.

Angesichts dieser bestehenden Unklarheiten schien es angezeigt, die mit Fällungen einhergehenden Immunitätsreaktionen artspezifischer Eiweißantigene erneut mit möglichst einfachen kolloidchemischen Modellen zu yergleichen, um durch Analyse der letzteren mit modernen Methoden und durch Feststellung ihrer quantitativen Reaktionsgesetze zu eventuellen Aufschlüssen in der einen oder anderen Richtung zu gelangen.

Für die Wahl der Kolloidmodelle was das Bestreben entscheidend, nur eine Reaktions- komponente, das Immunserum, mit einem Faktor bekannter chemischer Zusammensetzung zu vertauschen, die andere jedoch in Form von Zellen oder SerumeiweiB beizubehalten; dieser Weg bot mehr Aussicht als der Ersatz von Antikörper und EiweiBantigen durch zwei andere, aufeinander flockend wirkende Stoffe. Unter dieser Voraussetzung eröffneten sich zwei Möglichkeiten. Die eine bestand in der Substitution des Immunserums durch ein anderes Kolloid; oder man konnte daran denken, noch einen Schritt weiterzugehen, das dem Immunserum korrespondierende zweite Kolloid ganz wegzulassen und die Flockung des "Eiweißantigens" durch Kationen von höherer Fällungskraft, als sie den $\mathrm{Na}$ - lonen der $\mathrm{NaCl}$ - Lösung zukommt; $z u$ erzielen. In letzterem Falle entsprach allerdings das. Modell nicht mehr ganz dem Original; dafür ergaben sich aber relativ einfache Beziehungen und im Prinzipe livfen ja beide Methoden auf dasselbe hinaus, nur dab sich die erste als Umweg präsentierte, dessen eventuelle Bedeutung nachträglich ebensogut zu ermitteln war.

Im allgemeinen wächst die fällende Wirkung det Katioren mit ihrer Wertigkeit (H. Schulze, Hardy und Whetham). Es existieren jedoch neben der Wertigkeit auch noch andere Beziehungen. So konnte R. Min es zeigen, dab einfache und komplexe dreiwertige Kationen nur auf typische Suspensoide oder lyophobe Kolloide gleichartig einwirken, daB dagegen typische Emulsionen oder Emulsionskolloide nur gegen einfache dreiwertige Kationen empfindlich sind, nicht aber oder doch nur $100 \mathrm{mal}$ weniger gegen komplexe. In $5 \mathrm{~cm}$ verdünnten Eiklars erzeugten z. B. 15 Tropfen einer $\frac{\mathrm{m}}{100}$ Lösung von $\mathrm{Y} \mathrm{Cl}_{3}$ Trübung, während sogar 20 Tropfen einer $\frac{\mathrm{m}}{10}$ Lösung von $\mathrm{Co}\left(\mathrm{NH}_{3}\right)_{6} \mathrm{Cl}_{3}$ keine Eiweifflockung hervorriefen. Wie schon aus diesem Beispiel hervorgeht, hat $M$ ines hauptsächlich e i to Gruppe einfacher dreiwertiger Kationen, nämlich jerie der seltenen Erden (La, Ce, Y, Pr, Nd, Gd, Yb, Sm usw.) studiert : er tat dies, weil die Salze derselben in ihren Lösungen nicht der hydrolytischen Dissoziation unterliegen, wie das sonst bei den Salzen mehrwertiger (insbesondere vier- und fünfwertiger Ionen) meist der Fall ist (H. Ley). Solche Dissoziationen verändern nämlich die Wasserstoffionenkonzentration wie auch die Konzentration der freien Kationen des fraglichen Salzes und schalten dadurch Faktoren ein, welche 
die Beurteilung der reinen Kationenwirkung erschweren. Mines konstatierte nun, dab den dreiwertigen Kationen der seltenen Erden starke Giftwitkungen auf das ausgeschnittene Froschherz zukommen, ferner daB sie auf rote Blutkörperchen agglutinierend und wie bereits erwähnt, auf native Eiweißsole (Eiklar, Hämoglobin) flockend wirken; die letzten zwei Angaben lieben die Salze der seltenen Erden für die hier beabsichtigten $Z$ wecke als geradezu prädestiniert erscheinen.

In diesem Sinne sprachen auch andere Angaben in der Literatur. Biltz, Much und Siebert, Landsteiner und Jagič, Girard, Mangin und V. Henri hatten schon 1904 mitgeteilt, daB Hydrosole des Zirkon- und Thoroxyds, sowie jene der Kieselsäure Bakteriensuspensionen ausflocken. Indes handelte es sich hier um kolloide Verteilungsformen von Thoriumverbindungen. 1914 publizierte aber A. Sim on ini aus meinem Laboratorium eine Arbeit, in welcher er nachwies, dak der kolloide Zustand des Thoroxyds für die Agglutination nicht unerläBlich sei, sondern $\mathrm{dab}$ das gut kristallisierende Thornitrat schon in sehr niedriger Konzentration (1\%, und darunter) die verschiedensten Bakterienarten aus ihren Aufschwemmungen unter Verklumpung ausfällt. Frouin und Moussali, denen alle bisher zitierten Veröffentlichungen unbekannt geblieben zu sein scheinen, konnten in jüngster Zeit identische Beobachtungen über Bakterienagglutination durch Thornitrat und Lanthansulfat machen.

Nach allem gewinnt es den Anschein; als ob die fällende Kraft der Kationen seltener Erden auf Kolloide überhaupt und auf Emulsionskolloide speziell nicht allein auf ihrer Wertigkeit beruhen würde ; vielmehr dürfte dieser Kationengruppe eine kolloidchemische Sonderstellung*) zukommen, die sich in mehrfachen Belangen ăußert.

*) Die Behauptung von Frouin und Ledebt, daB man durch intraperitoneale und intravenöse "Immunisierung" von Kaninchen mit den Salzen seltener Erden hămolytische, inaktivierbare und durch Komplement reaktivierbare Ambozeptoren ohne Artspezifität (d. h. für alle möglichen Arten von Blutkörperchen) erhalt, wäre darnach angetan, diese Sonderstellung noch mehr zu markieren und grundlegende Vorstellungen der Immunitätslehre zu erschüttern. Sie erwies sich aber bei genauer Nachprüfung als irrig. Ich habe sieben Kaninchen durch vier Monate mit ziemlich großen Dosen von Thoriumsulfat, Cersuifat, Cerochlorid, Lanthannitrat, Praseodymnitrat usw, injiziert und nie eine Erhöhung der schon vor Beginn der Behandlung vorhandenen Normalambozeptoren oder eine Entstehung neuer hämo-
Damit war sonach die Zusammensetzung der geeignetsten Kolloidmodelle aus einer Zellsuspension oder einem Eiweißsol und einer (dialysablen) echten Lösung eines Salzes einer seltenen Erde entschieden. Leider war es aber nicht möglich, nur die nicht dissoziierenden Salze der dreiwertigen Kationen zu verwenden, auf welche sich $\mathrm{M}$ in a $\mathrm{S}$ beschränken konnte; zur Wiederauflösung (Dispersion) der Eiweibflockungen war ein kräftiger dispergierendes Kation notwendig und ein solches fand sich in dem vierwertigen Thorium. Da die Lösungen der Thorsalze stark dissozileren, so gelten natürlich für die im folgenden angestellten Vergleiche zwischen Thor-, Cer- und PraseodymVerbindungen die Einwände von $M$ ines. Indessen kam es hier fürs erste nur auf rohe Schätzungen an, und auBerdem spielt der Vergleich verschiedener Salze untereinander für das Wesen der Versuche und ihre Deutung keine entscheidende Rolle.

\section{Agglutination.}

Zu den meisten der nachstehend beschriebenen Versuche wurde neutrales, vom Kristallwasser befreites Thoriumsulfat $\mathrm{Th}\left(\mathrm{SO}_{4}\right)_{2}$ verwendet, welches sich in destilliertem Wasser und 0,85 proz. $\mathrm{NaCl}$-Lösung langsam (innerhalb von $1-3$ Stunden, je nach der herzustellenden Konzentration), aber völlig klar löst. Die notwendigen Verdünnungen wurden aus den ein- bis zweiprozentigen Stammlosungen durch Zusatz von Aq. dest. oder 0,85 proz. $\mathrm{Na} \mathrm{Cl}$ hergestellt. Mit Alkalikarbonaten liefern alle Thoriumsalzlösungen voluminöse, weiBlich-flockige Niederschläge, welche unter dem Mikroskop amorph aussehen. Setzt man Reaktionen von $\mathrm{Na}_{2} \mathrm{CO}_{3}$ und $\mathrm{Th}\left(\mathrm{SO}_{4}\right)_{2}$ in destilliertem Wasser an, und zwar derart, daß man bei konstanter Menge des einen Reagens das andere fortschreitend vermindert und umgekehrt, so kann man sich leicht überzeugen, dab solche Reihen eine untere und obere Hemmungszone erkennen lassen, mit anderen Worten, daB ein relativer KonzentrationsüberschuB eines Faktors die Bildung des Niederschlages verhindert.

lytischer Immunambozeptoren konstatiert. Der Irrtum der beiden Autoren dirfte darauf beruhen, dab sie es unterlielen, das Serum ihrer Kaninchen vor Einleitus:g der Injektionen auf den Gehalt an normalen Antikörpern auszuwerten ; die Titer, welche sie durch Zufuhs der seltenen Erden zu erzielen vermeinten, entsprechen in ihrer geringen Höhe durchaus den Wirkungsstärken normaler Kaninchensera. 
a) Reaktionsvolum $=3 \mathrm{ccm}$, konstante Menge Thorșalz, fallende Mengen $\mathrm{Na}_{2} \mathrm{CO}_{3}$.

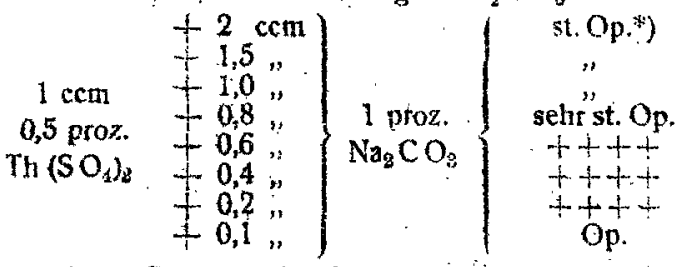

s) st. Op. $=$ starke Opa!eszenz, $++++=$ voluminöser, $+++\frac{1}{+}=$ mäBiger Niederschlag.

b) Reaktionsvolum $=3 \mathrm{ccm}$, konstante Menge $\mathrm{Na}_{2} \mathrm{CO}_{3}$, fallende Dosen Th( $\left.\mathrm{SO}_{4}\right)_{2}$.

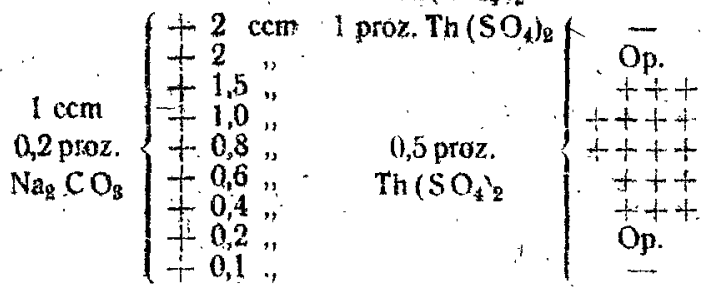

Die Niederschläge, welche sich bareits gebildet haben, lösen sich in einem Ueberschusse sowohl von Thorsulfat als von $\mathrm{Na}_{2} \mathrm{CO}_{3}$; das schliebliche Endprodukt kann nach den in der chemischen Literatur vorhandenen Angaben als Doppelsalz mit Soda: $\mathrm{Th}\left(\mathrm{CO}_{3}\right)_{2} \cdot 3 \mathrm{Na}_{2} \mathrm{CO}_{3} \cdot 12 \mathrm{H}_{2} \mathrm{O}$ unter besonderen VorsichtsmaBregeln isoliert werden. Sowohl die Hernmung der. Niederschlagsbildung durch relativen Konzentrationsüberschue eines Faktors als auch die nachtriag. liche Lösung der fertigen Nièderschläge in einer der beiden Reaktionskomponenten erinnern sehr. an die Verhältnisse bei der Präzipitation. lch inöchte hiexauf nicht weiter eingeben und nur bemerken, daß sich Niederschläge aus Thorsulfat und $\mathrm{Na}_{2} \mathrm{CO}_{8}$ auch in $\mathrm{Th} \mathrm{Cl}_{4}$ losen, nicht aber in Praseodymnitrat oder Cerochiorid, daB sich also anscheinend die Thorsalze gegenseitig vertreten können, nicht -aber die verschiedenen Kationen der seltenen Erden. Weiter wäre zu heionen, dab wie bekannt auch die Salze an. derer seltener Erden (Cer, Praseodym usw.) mit $\mathrm{Na}_{2} \mathrm{CO}_{3}$ Niederschläge geben, dab aber diese Reaktionen die Phänomene der. Henrmung und der Reversibilität durch Konzentrationsüberschuf eines Faktors nicht zeigen.

Thorsulfat agglutiniert alle (untersuchten) Bakterienatien, Hefezellen, Schimmelpilzsporen usw, und zwar in so siarken Verdinnungen, dab die Agglutination als bequemes Mittel zam Nachweis freier Thorsalze in wasserigen Flissigkeiten verwendet werden kann, falls die Konzentrationen 1:5000-6000 nicht unterschreiten. Allerdings sind die Grenzverdännungen, in welchen Thor. sulfat noch agglutiniert, nicht immer die gleichen und hängen wie bei der Immunagglutination von der Dichtigkeit der benutzten Bakteriensuspension, dann aber auch von der Art der Mikroorganismen $a b$.

Agglutination verschiedener Mikroorganismendurch Thorsuif at (Reaktionsvolum $2 \mathrm{ccm}$ ).

\begin{tabular}{c|r|r|r|r}
\hline $\begin{array}{c}\text { Thor- } \\
\text { konzentr. }\end{array}$ & Staphyl. & $\begin{array}{c}\text { B. } \\
\text { mesent. }\end{array}$ & Anthrax & $\mathrm{X}_{19}$ \\
\hline $1: 1000$ & +++ & +++ & +++ & +++ \\
$1: 2000$ & ++ & ++ & +++ & $++t$ \\
$1: 4000$ & - & - & +++ & +++ \\
$1: 6000$ & - & - & +++ & + \\
$1: 8000$ & & - & +++ &
\end{tabular}

Im allgemeincn läßt sich sagen, daß Proteus- oder Typhusbakterien für solche Untersuchungen wegen ihrer leichien. Fällbarkeit geeignet sind und dab die Differenzen zwischen nalue verwandten Bakterienarten weder konstant noch groß genug sind, um darauf etwia eine Unterscheidung der Spezies zu basieren.

Erwärmen auf $56^{\circ} \mathrm{C}$ schwacht die Fälbarkeit nicht $a b$, längeres Kochen reduzlert sie ganz unbedeuterd, Erhitzen auf $70^{\circ} \mathrm{C}$ etwas, aber nicht wesentlich stärker; bei den Proteus- $\mathrm{X}_{19}$ Stämmen ergeben sich daher wesentliche Unterschiede gegenüber der Agglutination durch Fleckfieberserum auf die ich an anderer Stelle zurückkommen werde. Die Verklumpung, welche sehr rasch (innerhalb weniger Minuten) eintritt, ist irreversibel; nach wiederholtem Waschen und Wiederaufschwemmen der Thorbakterien in$\mathrm{NaCl}$-Lösung erfolgt die Flockung und Sedimentierung stets mit unverminderter Geschwindigkeit.

Ein Ueberschu von Thorsulfat verhindert die Ausflockung; diese "nuteren Hemmungszonen " sind in der Regel sehr deutlich markiert:

Agglutination yon ryphusbazillen durcin Thorsulfat (Reaktionsvolum $2 \mathrm{ccm}$ ).

$\begin{array}{cc}\text { Thorkonzentration } & \text { Ergebnis } \\ 1: 135 & - \\ 1: 166 & - \\ 1: 250 & ++ \\ 1: 500 & ++t+ \\ 1: 1000 & +t+t\end{array}$

Thorsulfat und andere wasserlösliche Thorsalze schädigen lebende Zellen und töten dieselben bei genùgender Konzentration und Einwirknugsdater $a b$, sind somit ziemtich intensive Gifte für pflanzliches oder tierisches Protoplasma. Soweit es sich urn Bakterien handelt, haben schon A. Simonini sowie Frouin u. Moussai über 
desinfektorische Effekte der Thorverbindungen sowie der Salze anderer selteper Erden berichtet; diese Angaben konnte ich bestätigen und für tierische Zellen (Trypazosomen, Spirochaeten, Infusorien usw.) erweitern: Es ergahen sich hierbei sehr interessante Details, speziell auch in morphologischer Beziehung; von denen ich nur einige wenige, für den Mechanismus der Agglutination wichtige punkte hervorhebe.

Bewegliche Zellen werden durch Thorsultat schon in sehr starken Verdüntiungen immo. bilisiert und eigentürmlich starr; doch ist der Verlust der. Beweglichkeit keineswegs gleichbedeutend mit dem Zelttode, der erst spáter und bei höheren Konzentrationen erfolgt, abei die Empfindlichkeit der Zelle von ihrer Art abluangt. Typhusbazillen z. B. werden schon durch Verdünnungen vờ 1:5000 partiell geschädigt, durch solche von $1: 2000$ bereits in 7 Minuten (vielleicht auch noch frühtr) abgetötet; Naganatrypanosomen verlicren ihre Motilität in $1 \%$ Thorsulfat schon in wenigen Sekunden, thre Infektiositär für weibe Mäuse in längstens 15 Minuten; Rekurrensspirochaeten dagegen werden zwar auch rapide gelähmt, sind aber noch nach 55 Minuten langem Aufenthalt in $1 \%$ Thorsulfat infektiös. und ertragen sngar eine 10 Minuten lange Einwirkung von $2 \%$ Thorsulfat ohne Einbube der Virulenz. Erst ein $15-30$ Minuten langer Aufentbalt in $2 \%$ Thorsulfat schädigt die Rekurrensspirochaeten so weit, daß sie weiße Mäuse bet intraperitonealer Infekion nicht mehr zu infizieren vermögen.

Bakterien- und Schimmelpilz-Sporen sind seht resistent und werden selbst durch meltrtägiges Liegen in $1-2 \%$. Thorsulfat ihrer Wachstumsfähigkeit iicht beraubt. Offenbar beruht diese Resistenz auf der Impermeabilität der Sporenmembran, so dal also das Thorium mit Sporeninhalt gar nicht in Kontak̆t reten kann; da aber die Sporen ebensogut aghlutinabel sind wie die vegetativen Fomen, darf man wohl schlieken, daß die Agrlutinationblob durch Beeinflussung oder Verändering der äuBeren Zelloberfläche zustande kommt, nicht aber durch engere Wechselwirkung. von Protoplasma-Fiweit und Thor-Kation. Wabrschenlich gilt das für die Imtrunagglutination in gheicher Weise wie fur das Batterien-Thor-Modell.

Die Unabhängigkeit der $A$ ghgtutination lehender Zellen von hiter Abictung zeigt sich torigens nicht nur bei den Sporen, bundern auch bei den vegetativen Balterienformen. Hohe Konzentrationân von Tiu: sulfat 1 i: 100 ) agglubinteren nicht (untere Hemmungszone), töten aber ab; starke Verdünnungen dagegen $(1: 4000)$ flacken oft noch Bakteriensuspensioneri aus, ohne (bei entsprechender Einwirkungszeit) die Wachstumsfähigkeit zu vernicliten.

Mit Hilfe der Aggiatination läßt sich auch die Dialysierbarkett des Thorsulfats sehr einfach nachweisen. Füllt man nämlich ein- bis zweiprozentige Lösungen von Thorsulfat tin Aq. dest. oder in $0,85 \mathrm{proz} . \mathrm{NaC}$ ) in Fischblasen, Pergamentschläuche, $\mathrm{Ab}$ d e $\mathrm{r}$ h a ld e n'sche Hü!sen, deren Undurchlässigkeit für echte Kolloide geprüft wurde, und dialysiert gegen destilliertes Wasser oder 0,85 proz. $\mathrm{NaCl}$, so findet man in der Innen- und AuBen-Flüssigkeit nach relativ kurzer Zeit den gleichen Gehalt an freiem Thorsalz, was durch den gleichen wagglutinierenden Titer" für eine bestimmte Bakterienart ohne besondere Mühe festzustellen ist. Diese Versiche wurden so oft und mit so verschiedenen Dialysiermembranen wiederholt, daß kein Zweifel bestehen kann, daß die agglutinierende Wirkung dem gelösten, dialysablen und kristallisierbaren Thorsulfat als solchem und nicht tetwa einer kolloiden Verunreinigung (etwa mit Thoroxyd) zukommt. Uebrigens agglutinieren auch andere Thorsalze wie $z . B$. Thorchlorid, Thornitrat, Thorammoniumnitrat, welche sãmtlich gut kristallisieren und dialysieren; ferner kann man Aggiutinationen auch mit den Salzen anderer șeltener Erdea (geprüft wurden Lanthannitrat, Praseodymnitrat, Cerochlorid, Ceroammoniumnitrat) ausführen, so dab die Koniposition des hier benützten Modelles aus einem Eiweißkolloid (Zellsuspension oder Sol) und einem fällenden Elektrolyten (mit einem hoehwertigen Kation aus der Gruppe der seltenen Erden) gesichert erscheint: Vor Cero-, Praseodym- oder Lanthan-Salzen sind behufs Ausflockung höhere Konzeritrationen erforderlich; vergleichende Studien wurden angestellt, sind aber für unsere Betrachtung nicht wesentlich, können daher hier übergangen werden.

\section{Prizipitation.}

Thorsulfat gibt mit Serum Niederschläge, welche in destilliertein Wasser und 0,85 prozen tigsm $\mathrm{NaCl}$ unlöslich sind, welche sich dagegen in $\mathrm{NaOH}$ glatt (wie spezifische Präzipitate) losen.

Für die Entstehurg der Niederschiäge ist das Verhalthis der Mengen (Konzentrationen) der beiden Reaktionskomponenten zueinander entscheidend, insofern als ein relativer Uebersisuk ron Thorsulfat oder auch umgekehrt von Serum dic Praxipitation valllig hindert; diese 
„unteren Hemmungszonen " sind absolut gesetzmäBig, falls man gleiche Reaktionsbedingungen wählt und insbesondere auch das gleiche Serum benütat. Es ist ja bekannt, daB der EiweiBund speziell der Globulingehalt der verschiedenen Tiersera differiert, woraus sich natürlich Verschiebungen der Fällungsgrenzen ergeben müssen, wie der folgende Versuch lehrt, der auch die untere Hemmungszone bei Thor- bzw. bei relativem Serum-UeberschuB gut erkennen läßt.

\section{Versuch.}

Reaktionsvolum $3 \mathrm{ccm}$. Jedes Röhrchen enthalt $2,5 \mathrm{~cm}$. einer Serumverdünnung von $1: 10$, dann die angegebene Menge $\mathrm{Th}\left(\mathrm{SO}_{4}\right)_{2}$ in 0,85 proz. $\mathrm{NaCl}(0,5 \mathrm{ccm})$.

\begin{tabular}{|c|c|c|c|c|}
\hline \multirow{2}{*}{$\begin{array}{c}\text { Thordosis } \\
\text { g }\end{array}$} & \multicolumn{4}{|c|}{ Serumart: } \\
\hline & Pferd & Rind & Kaninchen & $\begin{array}{c}\text { Meer- } \\
\text { sehweinchen }\end{array}$ \\
\hline 0017 & - & & - & - \\
\hline & Op. & f. - & - & - \\
\hline $\begin{array}{l}0,0005 \\
0,00066\end{array}$ & $\begin{array}{c}\text { st. Op. } \\
+\end{array}$ & Op. & $\underset{+}{O p}$ & $\begin{array}{l}\text { Op. } \\
\text { st. Op. }\end{array}$ \\
\hline 082 & +1 & $+t$ & $+t$ & " \\
\hline 0013 & $\begin{array}{c}+t+ \\
++t+\end{array}$ & $\begin{array}{l}+t+ \\
++t+\end{array}$ & $\begin{array}{c}+4+\frac{1}{+} \\
++t+t\end{array}$ & + \\
\hline 7 & st. Op. & $r+t+$ & +++ & $"$ \\
\hline 00 & "op". & $+t+1$ & st & 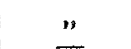 \\
\hline & $\mathrm{Sp}$. & & Op. & 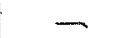 \\
\hline & - & st. Op. & & - \\
\hline 6 & - & Op. & - & - \\
\hline 0,02 & $\ldots$ & & $\ldots$ & - \\
\hline
\end{tabular}

Das eiweiBarme Meerschweinchenserum bleibt also unter diesen Reaktionsbedingungen schon bei Zusatz von $10 \mathrm{mg}$ Thorsulfat klár, dás eiweibreiche Rinderserum benötigt bei gleichem Volum das Doppelte, falls die Entstehung einer Dispersitätsverminderung der Globuline hintangehalten werden soll.

Ganz ähnliche Reihen resultieren, wenn man das Quantum Thorsulfat konstant hält (z. B. $1 \mathrm{mg}$ in $2 \mathrm{ccm}$ Reaktionsvolum) und den Serumzusatz abstuft, wie im folgenden, mit Pferdeserum ausgefïhrten Versuch :

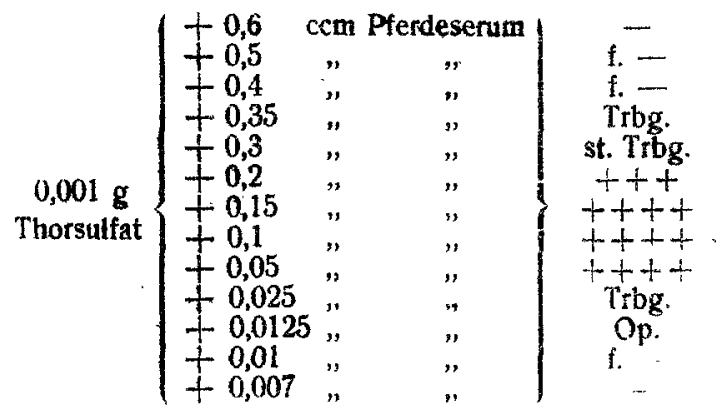

Bei 2 ccm Reaktionsvolum liegt somit die Reaktionsbreite des Pferdeserums mit $1 \mathrm{mg}$ Thorsulfat $z$ wischen 0,025 bis $0,35 \mathrm{ccm}$, falls man das Auftreten deutlicher Verminderungen der Transparenz als Indikator verwendet, und $z$ wischen 0,035 bis 0,25 , wenn man einen Niederschlag erhalten will. Die Reaktionsbreite ist daher ziemlich gering, die absoluten Mengen Pferdeserum sind relativ groB. Vergleicht man obige Reihen mit Auswertungen einer konstanten Präzipitinmenge gegen fallende Antigendosen und umgekehrt mit Titrationen eines konstanten Antigenquantums gegen abgestufte Volumina Präzipitin, so wird es ohne weiteres evident, dab man mit Hilfe von Pferdeserum sehr geringe Konzentrationen von Thorsulfat nachweisen könnte, daß dagegen Thorsulfat kein besonders empfindliches Reagens für Serumeiweiß datstellen würde.

So wie Thorsulfat und andere wasserlösliche Thorsaize fällen auch wasserlösliche Salze des Cers, Praseodyms usw. Serumeiweih; es ergeben sich dabei analoge quantitative Verhältnisse zwischen Eiweib- und Salzkonzentration, vor allem tritt auch der hemmende Einflub des einseitigen Ueberschusses einer Reaktionskomponente sehr prägnant in Erscheinung, aber die absoluten Zahlen sind natürlich ganz andere. Würde man z. B. bei einem Reaktionsvolum von $2 \mathrm{ccm} 0,001 \mathrm{~g}$ Cerochlorid mit fallenden Mengen Pferdeserum z. B. 0,2-0,002 ccm versetzen, so würden - wie man sich leicht überzeugen kann - alle Röhrchen klar bleiben und nur im Bereiche von eiwa $0,1-0,02 \mathrm{ccm}$ wäre eine Spur Opaleszenz wahrzuriehmen. Erhöht man jedoch die absolute Menge und damit die Konzentration des Cerochlorids ebenso wie jene des Pferdeserums auf das Zehnfache, so erhält man nachstebende Reihe:

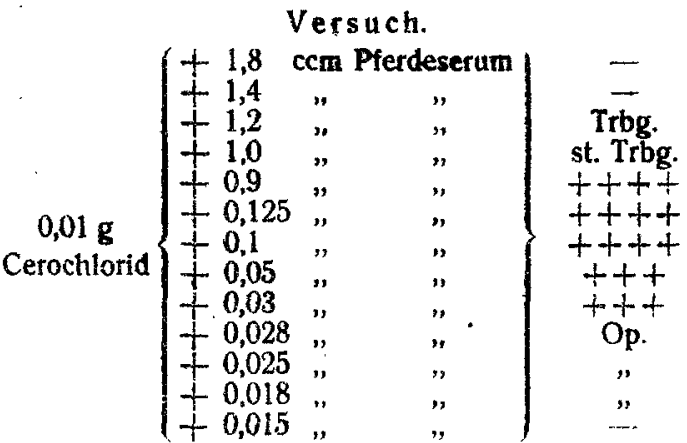

In $2 \mathrm{ccm}$ Reaktionsvolum liefern also $10 \mathrm{mg}$ Cerochlorid mit $0,03-1,0 \mathrm{ccm}$ PferdeserumNiederschläge. Es wäre aber irrig, daraus folgern zu wollen, daf im gleichen Reaktionsvolum $1 \mathrm{mg}$ 
Cerochlorid mit $0,003-0,1 \mathrm{~cm}$ Pferdeserum unter Niederschlagsbildung reagieren müßte; vielmehr erhält man dann für beide Reaktionskomponenten Konzentrationen, welche unter der Reaktionșschwelle liegen, während sie beim Thorsulfat - wie wir gesehen haben - zum Teil $(0,035-0,1 \mathrm{ccm}$ Pferdeserum) in das Bereich der starken Niederschläge fallen. $\mathrm{Ob}$ somit ein Präzipitat entsteht oder nicht, hängt davon $a b$, dab ein bestimmtes Verhältnis zwischen den Konzentrationen von Serumeiweiß und von fällendem Salz der seltenen Erde besteht, sondern wird auch noch dadurch bestimmt, daf diese Konzentrationen einen gewissen Schwellenwert nicht unterschreiten, der für Thorsalze $z$. B. weit niedriger ist als für Ceroverbindungen. Diese Schwellenwerte können bestimmt werden, indem man von einem optimalen Reaktionsgemisch ausgeht ${ }^{\text {Th }}$ und nun unter Beibehaltung des Reaktionsvolums sowohl das fällende Salz als auch das Pferdeserum gleichmäBig, d. h. ohne Aenderung ihres Verhältnisses zueinander fortschreitend abnehmen läBt, wie das die nachstehenden Beispiele illustrieren.

Versuch.

a) mit Cerochlorid. - Volum $2 \mathrm{ccm}$.

$0,01 \mathrm{~g}$ Cerochlorid $+0,5 \mathrm{ccm}$ Pferdeserum ++++

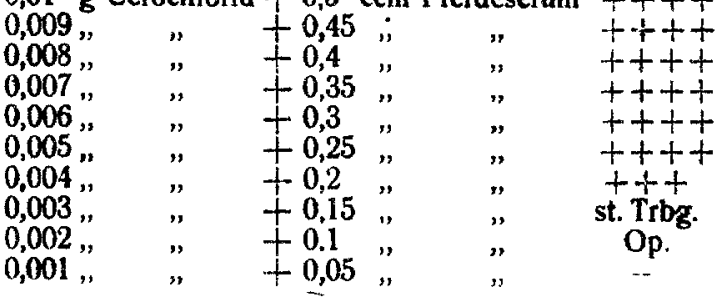

b) mit Praseodymnitrat. - Volum 2 ccm. $0,005 \mathrm{~g}$ Pras.-Nitr. $+0,25 \mathrm{ccm}$ Pferdeserum +++

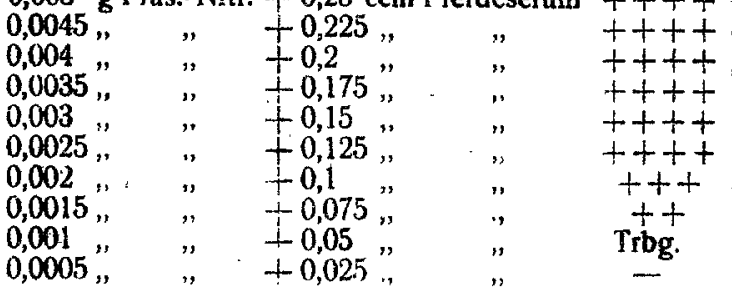

c) mit Thorsulfat. - Volurn $2 \mathrm{ccm}$. 0,001 g Thorsulfat $+0,1 \mathrm{ccm}$ Pferdeserum ++++ $0,0009, " \quad+0,09 ", 00,+++$

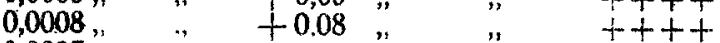
$0,0007 "$ " $\quad+0,07$ " $\quad ", \quad 1+++$ $0,0006, " \quad+0,06 ", \quad, \quad++++$ $0,0005 . . \quad " \quad+0,05 \% "$ " $"$ " +++ $0,0004, " \quad+0,04, ", ", \quad+++$ $0,0003, " \quad+0,03, " \quad . \quad$ Trbg.

$0,0002, " \quad+0,02 ", \quad, \quad$ Op.
$+0,01$
Sehr bemerkenswert ist die Reversibilität der Niederschläge, $d, h$. die spontane Rückverwandlung des Koagels in ein Sol bei Zusatz einer der beiden Reaktionskomponenten, wozu allerdings von letzteren weit höhere Konzentrationen notwendig sind als jene, welche zur Verhinderung der Niederschlagsbildung ausgereicht hätten. Mischt man z. B. $1 \mathrm{ccm} 1 / 10$ Pferdeserum $(0,1 \mathrm{ccm}$ konzentriertes Pferdeserum) mit $0,2 \mathrm{ccm} 0,5$ prozentigen Thorsulfat, so entsteht sofort ein mächtiges Präzipitat, zu dessen Lösung ca. $0,9 \mathrm{ccm}$ einprozentiges Thorsulfat oder etwa $1,5 \mathrm{ccm}$ konzentriertes Pferdeserum benötigt werden, während die Hemmung der Ausflockung im ursprünglichen System schon mit weit geringeren Mengen Salz oder Serumeiweib zu erzielen wäre (vgl. die Tabellen). Die Lösung erfolgt in allerkürzester Zeit, innerhalb einiger Sekunden, und entspricht einer maximalen Dispersion der ausgeflockten Substanzen, wie das aus der vollkommenen Durchsichtigkeit der resultierenden Flüssigkeiten hervorgeht.

Dabei können sich die verschiedenen Sera gegenseitig vertreten: ein Präzipitat aus Pferdeserum löst sich also auch in Rinder-, Menschenund Meerschweinchenserúm. Ebenso ist eine Substitution der Salze verschiedener seltener Erden möglich, so daß z. B. Präzipitate, die man mit Cerochlorid oder Praseodymnitrat dargestellt hat, sofort in den Solzustand übergehen, falls man sie mit einer genügenden Menge "entsprechend konzentrierten Thorsulfates in Kontakt bringt, und umgekehrt. Die lösende Wirkung ist der fällenden im allgemeinen proportional ; Thorsalze lösen also besser (in geringeren Konzentrationen) als Cer-oder Praseodym-Verbindungen. Altern der Niederschläge vermindert ihre Reversibilität nicht; Präzipitate, aus Menschenserum und Thorsulfat gewonnen, lieben sich noch nach Wochen und Monaten (feuchter Aufbewahrung) ebenso prompt in Rinderserum oder Thorsulfat lösen wie am ersten Tage ihrer Entstehung.

Spezifische Präzipitate (gewonnen aus Eiweißantigen und präzipitierendem Immunserum) lösen sich in Thorsulfat gleichfalls schnell und vollständig, eine Tatsache, die theoretisch und praktisch (versuchstechnisch) Bedeutung hat. Aus dem Kolloidmodell dürfen wir wohl den SchluB ableiten, daB die bei demselben beobachtete EiweiBflockung ebenso wie die Reversion der Flockung durch UeberschuB einer Reaktionskomponente rein physikalische Vorgänge sind, welche das Eiweib selbst chemisch intakt lassen. Das geht auch daraus hervor, 
Lak das durch Thorsulfat gefallte Serumeiweje sowohl als solches. wie auch nach der Wiederauflösung in Thorüberschuf seine Antigenspezifităt unverändert beibehalt; iman kann mit solchen Präparaten Meerschweinchen spezifisch sensibilisieren und bei sertsibilisierten Meerschweinchen durch intravenòse Injektion Schock auslösen. Leizteres Experiment gelingt auch mit den gewaschenen Thoreiweifpräzipitaten, da sie im Biutplasina der gespritzten Tiere offenbar ebenso glatt in Lösung gehen wie in der Eprouvetie bei der Vermengang mit konzentriertem Meerschweinchenserum. Da nun spezitische Präzipitate durch. Thorsulfat in der gleichen Weise, d. $h$, auf rein physikalischem Wege dispergibel siud, so liegt die Annahme nicht fern, daß -auch der Flockungsvorgang, dem sie ihre Bildung verdanken, ein physikalisches und kein chemisches Geschehen repräsentiert Technisch erscheint die Möglichkeit einer kompletten, durchsichtige Flüssigkeiten licfernden Lösung spezifischer Präzipitate in Thorsulfat vertvoll, weil diese Prozedur, welche $z$ weifellos weniger eingreifend ist als die Lösung in $\mathrm{NaOH}$, die Aussicht auf eine optische Analyse des "Präxipitationsphänomens, wie sie $H$ irsch und Langenstrab versucht haben, yerbessert und das von Doerr und Moldovan begonnene Studium der Zusamniensetzung spezifischer: Präzipitate mit Hilfe der Anaphylaxie wesentlich erleichteri. Endlich wäre zu erwägen, ob man durch Fallung schwacher Immunsera mit Thorsulfat und Wiederauflösung des Koagels in Immunserum gleicher. Art nicht eine Konzentration der Antikörper herbeiführen könnte; ein Vorversuch in dieser Richtung fiel befriedigend aus. Für therapeutisch anzuwendence Heilsera (nach Art der von Gibson, Banzhof, Homer u. A. durch Ammonsutrat konzentrierten Diphtherie- und Tetanussera) mibte man allerdings erst die Giftwirkung der Salze seltener Erden genauer ermitteln, da z. B. Mines gezeigt hat, da $B$ dreiwertige Ionen seltener Erden (La, Ce, Y, Pr, Yb, Sm usw.) schon inVerdännungen vori $0,000001 \mathrm{n}-0,00001 \mathrm{n}$ Stillstand des ausgeschnittenen Froschherzens berbeiführen, und dab dieser Stillstand im allgemeinen schwer zarückgeht uad speziell bei blober Entfernung des aktiven lonen uus der Durchspülungsflussigkeit nur langsam der Erholung weicht. Es erscheint aber fraglich, ob im Organismus analoge Verhälnisse bẹstehen wie in solchen Experlnenten. Meerschweinchen von $390-420 \mathrm{~g}$ ertrugen die rasche intravenöse Injektion vón $1,2-8,5 \mathrm{ccm} 0,5$ prozentiger Lösung von Thor- sulfat ohne sichtbare Störung und bei Kaninchen yon $2000 \mathrm{~g}$ konnte ich $2 \mathrm{ccm}$ einer einprozentigen Lösung von Thorsuliat oder $2 \mathrm{ccm}$ einer zweiprozentigen Lösung von Cerochlorid bzw. Prasendymnitrat in einem Schub in die Obrvenen einspritzen, ohne daB die Tiere auf diesen Eingriff unmittelbar reagiert hätten. Erst auf die intravenöse lojektion von $2 \mathrm{ccm}$ einer zwejprozentigen Lösung yon Thorsulfat erfolgte bei einem Kaninchen von $1800 \mathrm{~g}$ nach wenigen $\mathrm{Mi}$ nuten eln schwerer anaphylaktoider Anfall; die Atmung setzto nach einigen schnappenden Respirationen völlig aus, die Bulbi traten hervor, der Cornealreflex schwand gänzlich und das Tier lag wie tot da. Nach einigen weiteren Minuten wurden ganz seichte, allmählich sich vertiefende Atemzüge bemerkbar, die Cornealreflexe stellten sich wieder sukzessive ein und wurden normal, das Kaninchen setzte sich auf und war innerbalb einer Viertelstunde so weil erholt, daf es vorgelegies Futter frah. Meines Erachtens war der Symptomenkomplex nicht auf die Vergiftung des Herzens durch das Thorkation zu beziehen, wogegen das rasche Zurückgehen der Erscheinungen sprach, sondern auf eine intravaskuläre Prïzipitation der Globuline des Blutplasmas durch das. Thorsalz und eine Reversion dieser Flockung durch das überschüssige Blutplasma; welches die noch tunktionierende Herzaktion an die Stätten der Koagulation heranbrachte; es dürfte sich also hier um ähnliche Prozesse handeln, wie sie nach der direkten. Einbringung kolloider Kieselsäure in die Blutbahn aufreten (Doer und Moldovan). Allerdings könnte beim Thorsulfat eberiso wie bei der kolloiden Kieselsăure auch Hămagglutination im Spiele sein; aber diese tritt in vitro langsamer ein als die fast momentane Globulinflocknng und wird überdies durch das Plasma, welches in gewissem Sinne als Schutzkollojd fungiert, verzögerr oder gestört.

Die Schutzwirkung der Eiwejîkörper des Plasmas , ist es auch, wenn die am. Froschherzen beobachtete Vergiftung des Herzmuskels durch intravenös injiziertes Thorsalz oder ähnliche hochwertige Kationen selfener Erden ausbleibt. Das Thorsalz bleibt nämlich nicht frei, sondern geht mit dem Serum-(Plasma-) Eiweib lockere Verbinaungen "Thoralbuminate" ein, in analoger Weise wie das G. G a le otti für die Präzipitationse, scheinungen zwischen Eier-(Serum-) Albumin und Sehwermetallsalze $\left(\mathrm{CuSO}_{4}\right.$ oder $\mathrm{AgNO}_{3}$ ) beschrieben hat; mit diesen Eiwein: flockungen durch Schwermetallsalze teilen ja die hiet geschilderten Eiweibfällungen durrch 
seltene Erden dic Reversibilitat, die Loslichkeit der Niederschlage in Leberschut der einen oder der anderen Reaktionskomponente. ein Phäro. men, dessen Gesetzmärigkeiten für GichwometaliEiweibsysteme $\mathrm{O}$ a le " it i graphisch darzustellen vermochte. Dab tatsichlich solche Bindungen eintreten, welehe in Reaktionsgemisch vorhandene lebende Zellen vor der Giltwirkung der Thorsalze cbenso schützen, wie eiwa Scrumeiweib die desinfektorische $\mathrm{K}$ ! aft ron $\mathrm{HgCl}_{2}$ ab schwächt, geht aus dem nachstehenden Versuch hervor, demzufolge Thnrsulfat in leitungswasser metr als zehnmal so stark bakterizid wirkt als in Peptonbouillon.

\section{Versuch.}

Zwai Reihen Eprouvetten, die eine mit je $10 \mathrm{ccm}$ Peptonbouilion, die andere mit je $10 \mathrm{ccm}$ sterilem Leitungswasser erhalten fallende Zusätze von Thorsulfat und werden mit je $0,05 \mathrm{ccm}$ einer dichten Typhus: bazillen-Emulsion beimptt. Nach 20 stïndiger Einwirkungsdauer wird je eine Oese aus jeder-Eprouvette zu einer Gelatineplatte verarbeitet.

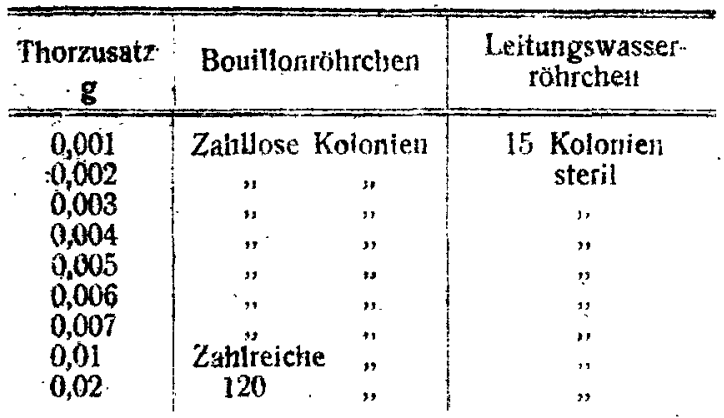

Die Bindung des Thorsalzes an das Eiweib zu einem kolloidchemisch unwirksamen Komplex kann auch dadurch demonstriert werden, dab nach der Ausflockung einer Serumlösung mit : Thorsulfat die über dem Niederschlag stehende. Flüssigkeit nicht mehr agglutinierend (auf Bakterien) wirkt. Ferner kann man weder aus der überstehenden Flüssigkeit noch aus dem Niederschlage durch Dialyse gegen destilliertes Wasser das Thorsulfat in aggiutinierend wirkenden Mengen abspalten.

\section{Versuch.}

$5 \mathrm{~cm}$ Rinderserum $+20 \mathrm{ccm} 0,85$ prozentige $\mathrm{NaCl}$ Losung $+5 \mathrm{~cm}$ einprozentiges Thorsulfat geben eine starke Fallung mit kiarer, libersteinender Flüssigkeit. Die einprozentige Thorlosung hat dabei eine sechslache Verdiunnung erfahren; wäre das Thorsalz an der Reaktıon unbeteiligt, so müBte die uiberstehende Flüssigkeit noch in 10 - 12 facher Diluition $\mathrm{X}_{19}$-Bazillen ausflocken; sie erweist sich aber auch im konzentrierten Zustaride als unwirksam.

Der Niederschlag wiro gegen gröBere Mengen destilliertes Wasser in Hülsen von Sch le I ch e $\&$ S Sch iill dialysiert: die AuBenflüssigkeiten werden auf $20 \mathrm{ccm}$
Volum eingedampl, agglutinieren abu weder in konzentrierten nocll im verdunten Zustande $X_{19}$.

Die bei der Dialyse dei tiberstehenden Flüssigheit gewonnene AuBenflüssigkeit, anf $3 \mathrm{crm}$ eingeinmpit, aggintiniert ebensowenig.

Anch durch Vetaschen des Niederschlages und Ausiaugen der Asche mit Wasser läBt sich das Thor richt ais Agglutinin gewimen, was sich wohl aus der Veberfilhrung des Thorsulfates oder Thorhydroxyds in unissliches Thoroxyd durch den Glïhprozes erklart.

Löst mat Thoreiweibratipitate in EiweibuberschuB $z$. B. in konzentriertem Pferdeserum und dialysiert man die erhaltene klare Lösung gegen destilliertes Wasser, so enthäli die Außenflüssigkeit keine nachweisbare Spur von agglutinierendem Thorsalz. Der Inhalt der Hïlse erscheint stark getrübt, offenbar weil die Globuline infolge des Abdialysierens der Serumsalze ausflocken; setzt man $\mathrm{NaCl} z u$, so erfolgt völlige Klärung.

Nimmt nau die Lösung elnes Thorpräzipitates in Thorsulfat vor, so gestalten sich die Dinge wie folgt:

\section{Versuch.}

$1 \mathrm{ccm}$ Pferdeserum $+9 \mathrm{ccm} \mathrm{NaCl}+0,3 \mathrm{ccm}$ einprozentiges Thorsulfat gibt einen Nicderschlag, welcher durch Zentrifugieren und Waschicn isoliert und in $2 \operatorname{ccm} z$ veiprozentigem Thorsulfat gelöst wird. Diese absolut klate Lösung wird, gegen einmal gewechseltes Aq. dest. $(2 \times 20 \mathrm{~cm})$ dialysiert, opaleszent und kann durch Zusatz von $\mathrm{NaCl}$ nicht geklärt werden. Die Außenflüssjgkeit auf $1 / 10$ des Volums $(=4 \mathrm{ccm})$ eingedampft, sollte noch in hohen Verdünnungen (i:50-100) $\mathrm{X}_{10}$ agglutinieren, gibt aber nur im konzentrierten $\mathrm{Zn}$ stand Agglutination, $z$ weifach verdünnt binB andeutungsweise, vierfach verdünnt nicht metir.

Daraus erhellt, dab das Eiweib nicht nur in der Form des Kọagels Thorsalz festhält, sondern auch wenn es durch Thorsulfat- oder Serumüberschup wieder zum Sol dispergiert wurde; erst seht bedeutende Ueberschüsse werden frei und auch in Gegenwart von Eiweiß dialysabel.

III. OptischeAnatysedes Kolloidmodelles und der Immunpräzipiation.

Hierzu warde in allgemeinen die von P. Hirsch und K. La tigenstra 6 angegebenc und durchgebildete Methodik verwendet.

Fs wurden zunächst die Interferometerwenc (IW) der beiden gelösten Reaktionskomponenten in det $4 \mathrm{~cm}$-Kammer gegen eine Vergleichsflüssigkeit (meist eine bestimmte 0,85 prozentige $\mathrm{NaCl}$-Lösting) ermittelt und daraus der. IW eines Gicmisches gleicher Volumina beider Komponenten als arithmetisches Mittel der abgeJesenen Zahlen berechnet. Trat bei der Vermengung der Reaktionskomponenten eine Flokkung auf, so ergab sich für die überstehende 
Flüssigkeit ein IW, der hinter der für cias Gemisth errechneten Ziffer zuräckblieb; die Differenz soilte (wenigstens beim Kolloidmodell) dem Präzipitat entsprechen. Ich machte nun von der ausgezeichneten Dispergibilität der Niederschläge in einem Ueberschusse von Thorsalz Gebrauch und löste sie in Thorsulfatsolution von bekanntem $I \mathrm{~N}$, so dak das Gesamtvolum der Lősung dem Volum des Gemisches der beiden Reaktionskomponenten glich. Dadurch erfuhr der IW der Thorsulfatlösung eine $\mathrm{Zu}$ nahme, welche bei rein physikalischen Zustandsänderungen dem für das Präzipitat berechneten Differenzwert gleichen muBte. Beim Abmessen der Volumina wurden geaichte Pipetten benutzt und die oft sehr bedeutenden Mebfehler durch relativ grobe Volumina beider Reaktionskomponenten (mindestens $10 \mathrm{ccm}$ ) ausgeglichen. Die Niederschläge wurden scharf abzentrifugiert, die überstehenden Flüssigkeiten sorgfältig und vollständig abgesaugt.

\section{Versuch.}

Je $10 \mathrm{ccm}$ Pferdeserum (im Verhältnis von 1:20 mit 0,85 prozentigem $\mathrm{NaCl}$ verdünnt) $+0,05$ prozentige Thorsulfatlosung werden im Zentrifugenglas vermengt, die Flockung abgewartet, zentrifugiert, die überstehende Flüssigkeit abgesogen und bis zum ursprünglichen Niveau durch 0,5 Proz. Thorsulfat ersetzt, in welchem sich das Sediment kîar löst.

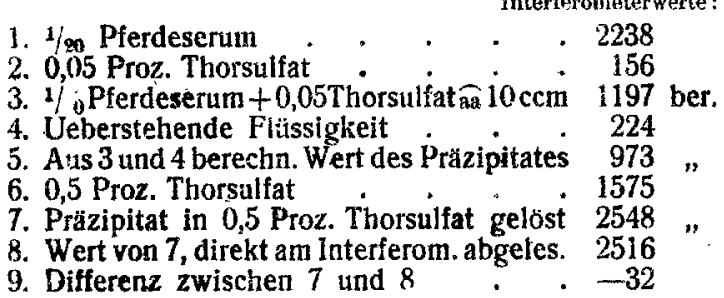

Versuch.

Hier wurde $40 \mathrm{fach}$ verdünntes Pferdeserum benutzt; die Verdürnnung erfolgte nicht mit 0,85 prozentigem $\mathrm{NaCl}$, sondern zum Teil mit Aq. dest., um einen niedrigeren IW zu erzielen. Von dieser Pferdeserumlösung wurden $50 \mathrm{ccm}$ mit $50 \mathrm{ccm}$ Thorlösung ( IW $=575$ ) vermischt, worauf starke Flocking eintrat; die überstehende Flüssigheit blieb aber leicht triube, war jedoch direkt interférometrierbar. Das Präzipitat wurde zuerst in $100 \mathrm{ccm}$ einer $z W$ eiten Thorsulfatlösung ( $I W=1544$ ) verteilt, löste sich aber nicht, so daß nun $z u$ dieser Mischung neuerlich $100 \mathrm{ccm}$ einer dritten Thorlösung $(I W=2206)$ zugesetzt werden muBten. Erst jetzt trat innerhalb von etwa 10 Stunden, aiso ziemlich langsam, komplette Losung ein. Trotz der vielen Manipulationen, war die erzielte Uebereinstimmung zwischen Beobachtung und Erwartung recht befriedigend:
1. $1 / 4$ Pferdeserun
$\cdot 734$
3. Gemisch aus ie $50 \mathrm{ccm} 1$ und 2 , 6.54,5 ber.
4. Ueberstehenće Filissigkeit

interferomuterwerte:
3 und 4 berechnet Interferoneser wel th

6. verteilt in $100 \mathrm{ccm}$ Thorlösung

$$
\text { von IW 1544 } 1822,5
$$

7. Mischung 6, geklärt durch Zusatz von $100 \mathrm{ccm}$ Thorlösung vom IW 22062014

8. Wert von 7 , direkt abgelesen . . 2010

9. Differenz $z$ wischen 7 und 8 . . 4

Berücksichtigt man die Fehlerquellen, welche sich bei den verschiedenen Prozeduren des Ansetzens der Reaktion, des Absaugens der überstehenden Flüssigkeit, des Wiederauffüllens mit der die Dispersion der Präzipitate bewirkenden Thorlösung ergeben, und stellt man dieselben der übermäßigen Empfindlichkeit des Interferometers gegenüber, so kann man wohl behaupten, daB die Abnahme des IW im Reaktionsgemisch durch die Entstehung des Niederschlages erklärt wird und dab der durch die Flockung hervorgerufene Substanzverlust (optisch gemessen) im Präzipitate fast quantitativ nachweisbar erscheint; bei Messungen mit dem Pulfrich'schen Refraktometer würden Differenzen von -32 bis - 4 Trommelteilen $z$ wischen Beobachtung und Berechning überhaupt nicht zum Ausdrucke kommen. Immerhin fiel es auf, daB bei sehr zahlreichen Versuchen dieser Art (vgl. auch weiter unten) die gefundene Differenz stets das gleiche Vorzeichen hatte, d. h. daß für das Präzipitat scheinbar stets kleinere IW beobachtet wurden als man erwartete, niemals größere. Eine analoge Erscheinung wurde aber auch konstatiert, wenn man das Verhältnis des Reaktionskomponenten so wählte, daß sich gar keine Flockung einstellte; es blieb dann der IW des Gemisches hinter dem berechneten Mittel zurück, selbst wenn nicht einmal eine wesentliche Transparenzverminderung erfolgte. Die Ursache der Differenz liegt also offenbar gar nicht im Präzipitat, sondern in der überstehenden Flüssigkeit, für welcha die optische Messung selbst bei ausbleibender Flockung zu kleine Ziffern liefert. Auf die möglichen Ursachen des geschilderten Verhaltens werde ich an anderer Stelle detaillierter eingehen.

Weiter bemerkt man, daB Thorsulfat unter Umständen einen sehr großen Teil des Serumeiweibes ausfällt, daB aber die sedimentierenden Substanzmengen je nach den quantitativen Reaktionsbedingungen variieren. Ersetzt man das Thorsulfat des Systemes bei gleichbleibender Menge (Konzentration) des Serumeiweibes durch Cerochlorid, so wird die optisch meBbare Substanzmasse des Präzipitates geringer, auch wenn man die Cer-Konzentration stark erhöht (stärkere Fallungskraft der Thor-Ionen). 
Versuch.

Je $10 \mathrm{ccm}$ Pferdeserum $(1: 200,85$ proz. $\mathrm{Na} \mathrm{Cl}$. Losung) wurden mit je $10 \mathrm{ccm}$ Thorsulfatverdünnung (in 0,85 proz. $\mathrm{NaCl}$ ) versetzt. Ijie. IW der Reaktionskomponenten betrugen:

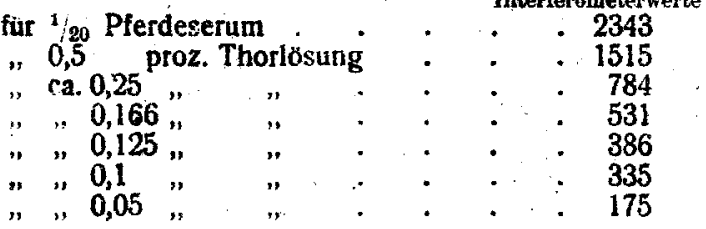

1. 1/20 Pferdeserum $+0,5$ proz. Thorlosung a. $10 \mathrm{ccm}$

2. Das Gemisch blieb fast ganz klar, der IW desselben betrug direkt abgelesen

3. Differenz zwischen Beobachtung und Berechnung

1888

$-41$

b)

1. 1/20 Pferdeserum $+0,25$ proz. Thorlosung $10 \mathrm{ccm}$

2. Das Gemisch war sehr stark trübe, schied aber kein Präzipitat ab; es konnte erst nach vierfacher Verdünnung mit 0,85 proz. $\mathrm{NaCl}$ interferometriert werden und hatte den aus dieser Ablesung ermittelten IW von.

$-1445$

3. Die Differenz war demnach . . . $-118,5$, c)
$1 / 20$ Pferdeserum $+0,166$ proz. Thortösung a $10 \mathrm{ccm}$
war noch stäker getrübt als $\mathrm{b}$, schied aber gleichfalls kein Präzipitat aus.

\section{d)}

1. 1/20 Pferdeserum $+0,125$ proż. Thorlosung as $10 \mathrm{ccm}$

2. Das Gemisch flockte aus, die überstehende stark trübe Flüssigkeit hatte

1364 ber.

3. Präzipitat berechnet als Differenz aus 1 u. 2

672

692

e)

1. ${ }^{1 / 20}$ Pferdeserum $+0,1$ proz. Thorlosung az $10 \mathrm{ccm}$. . . .

2. Präzipitation; tiberstehende, leicht trübe

Flüssigkeit
3. Differenz berechnet aus 1 u. 2 ( $=$ Prazipitat)

4. Prazzipitat, aufgelost in $20 \mathrm{ccm}$ Thorlösung vom IW 1515

5. Wert von 4 direkt abgelesen $\quad \cdot \quad \cdot 2408$
6. Differenz von 4 u. 5

$$
\text { f) }
$$

1. 1/20 Pferdeserum + 0,05 proz. Thorlösung $10 \mathrm{ccm}$

2. Ueberstehende Flüssigkeit $: \quad . \quad \vdots \quad 348$

3. Präzipitat, berechnet aus 1 4. 2 . . 911

Versuch.

Dieser Versuch wurde mit dem gleichen Pferdeserum und sechs verschiedenen Verdünnungen vor: Cerochlorid in 0,85 proz. $\mathrm{NaCl}$ in gleicher Weise angestelit. Die Cerochloridlossungen hatten nachstehende IW: ca. 1 proz. Cerochlorid (durch Verdïnnen bestimmt)

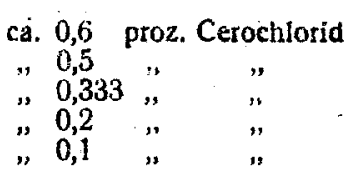

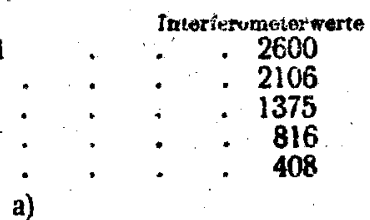

1. $1 / 20$ Pferdeserum +1 proz. Cerochlorid at $10 \mathrm{ccm}$. . . 3277,5 ber.

2. Präzipitat, aufgelost in Thorsulfat (1515) 1840

3 . " allein (2. minus Thorwert) 325

b)

1. 1/20 Pferdeserum $+0,6$ proz. Cerochlorid

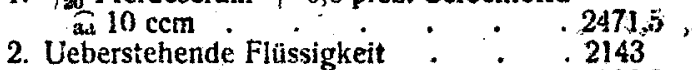

3. Präzipität als Differenz aus 1 u. 2 berechn. 328,5 "

4. " aufgelöst in Thorsulfat (1515) 1843,5 "

5 . " " " "beobacht. I625

6. Differenz zwischen Berechnung und Beobachtung

1. ${ }^{1 / 20}$ Pferdeserum $+0,5$ proz. Cerochlorid 2224,5 "

2. Ueberstehende Fluissigkeit . . 1917

3. Präzipitat, berechn. als Differenz von 1 u. 2307,5 ,

4. " aufgelöst in Thorsulfat (1510) 1817,5"

5. Wert von 4, beobachtet . . . 1782

6. Differenz von 4 und $5 \quad \because \quad: \quad-35,5$,

d)

1. ${ }^{1 / 20}$ Pferdeserum $+0,333$ proz. Cerochlorid an $10 \mathrm{ccm} \cdot 1859$

2. Ueberstehende Flüssigkeit : - 1557

3. Präzipitat, berechn. als Differenz von l u. 2302

4. " aufgelöst in Thorsulfat (1510) 1812

5. Wert" von 4, beobachtet.$? 1740$

6. Differenz von 4 und $5 \quad: \quad . \quad-70$

\section{e)}

1. $1 / 20$ Pferdeserum $+0,2$ proz. Cerochlotid 1579,5 ber.

2. Ueberstehende Flüssigkeit . . . 1342

3. Präzipitat, Differenz von 1 u. 2 , 237,5"

4. "aufgelöst in Thorsulfat (1515) 1752,5"

5. Wert" von 4, beobachtet . 1709

6. Differenz von 4 und 5 . . . $-43,5$

\section{f)}

${ }_{1 / 2 n}$ Pferdeserum $+0,1$ proz. Cerochlorid $\widehat{a a} 10 \mathrm{ccm}$ bleibt ganz klar.

Die Gegenüberstellung von Thorfällungen und Ctrfällungen ergibt also für die IW der Präzipitate folgende Zahlen; wobei die Reaktionsvolumina stets gleich $20 \mathrm{~cm}$ und die Konzentration des Pferdeserums gleich 1:40 gehalten worden war:

\begin{tabular}{|c|c|c|}
\hline $\begin{array}{c}\text { Konzentration } \\
\text { Proz. }\end{array}$ & Cerochlorid & Thorsulfat \\
\hline $\begin{array}{l}0,5 \\
0,3 \\
0,25 \\
0,1665 \\
0,125 \\
0,1 \\
0,083 \\
0,0625 \\
0,05 \\
0,025\end{array}$ & $\begin{array}{l}325 \\
347 \\
343 \\
372 \\
-781 \\
- \\
- \\
-7 \text { Zone d. rela- } \\
\text { tisen voher- } \\
\text { schussis von } \\
\text { Plerdeserum }\end{array}$ & $\begin{array}{c}- \\
- \\
- \\
- \\
- \\
- \\
- \\
092 \\
1025 \\
911 \\
\end{array}$ \\
\hline
\end{tabular}


Sehr interessant verhielt sich die Immunpräzipitation, welche ich vięrmal mit dem Interferometer analysierte. Die Reaktionsvolumina waren ebensogroB, wie bei den eben geschilderten Kolloidmodellen, nämlich gleich $20 \mathrm{ccm}$. Um möglichst ausgiebige Präzipitatianen 24 erreichen, wurden hochwertige Antimenschensera von Kaninchen (Nr. 43 u. Nr. 8) verwendet, welche mit hinreichend verdünntem $(1 / 400-1 / 80 n)$ Menschenserum nahezu momentan und schon bei Zimmertemperatur reagierten, wobei zunächst Trübungen entstanden, die sich rasch zu Flocken verdichteten; wach zwei bis mehrstündigem Zuwarten war Sedimentierung und Bildung einer klaren überstehenden Flüssigkeit eingetreten. Die Sedimente wurden mit der Zentrifuge komprimiert, von den überstehenden Flüssigkeiten sorgfultig abgetrennt und in Thorlösungen von bekanntem IW dispergiert. Da Präzipitate nur bel relativ hoher Konzentration des lmmunserums auftreten, niedrige Verdünnungen von Kaninchenserum mit 0,85 prozentiger $\mathrm{NaCl}$-Lösung jedoch mit dieser $\mathrm{NaCl}$-Lösung im Interferometer nicht mehr verglichen werden können, wurde den Immunserum-(Präzipitin-) Verdünnungen soviel destilliertes Wasser zugesetzt, bis sie gegen 0,85 proz. $\mathrm{NaCl}$ ablesbare Interferometerwerte gaben.

Versuch.

Interferometerwerle :

1. 1/200 Menschenserum (verduint mit 0,85 proz. $\mathrm{Na} \mathrm{Cl}$ )

271

2. ${ }^{1 / 20}$ Serum Kaninchen Nr. 43 (verdinnt mit 0,85 pioz. $\mathrm{NaCl}$ )

3. I/20n Menschenserum + ${ }_{120}$ Serum Nr. $43^{\circ}$ Tia $10 \mathrm{ccm}$

1992

eberstehende Flüssigkeit, beobachtet nach 24 Stunden

1131

ber.

1020

111

5. Präzipitat, Differenz aus 3 und 4

6. Thorsulfatlosung (1 Proz in Aq. dest.

7. Präzlpitail, aufgelöst in dieser Thorlösung

8. Wert von 7 , direkt abgelesen .

9. Differenz zwischen Berechnung und Beobachtung

\section{Versuch.}

1. Menschenserum wie im Vorversuch

2. Konzentriertere Lösung von Serum 43 (mit Aq. dest)

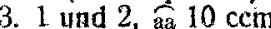

4. Ueberstehende FIüssigkeit, abgelesen nach 2 Stunden

5. Präzipitat, berechnet aus 3 und 4

6. 5 aufgel. in Thorsulfatlösung $(I \mathrm{~W}=31$ )

7. 6 direkt abgelesen

8. Differenz $z$ wischen 6 und 7

$$
\text { Versuch. }
$$

1. 1/200 Menschenserum (andere Probe!)

2. Serum Kaninchen Nr. 8 (verdiinnt mit Aq. dest. seht konz.!)
3. Interfervineterwerte:

4. Ueberstehende Flussigkeit . . 893

5. Präzipitat, berechnet ais Differenz von 3 und 4

6. Prázipitấ, aufgelost in 1 proz. Thorsulfat (IW $=31$ )

7. Wert von 6 , beobachtet . . . 440

8. Differenz von 6 und $7 \quad \cdot \quad . \quad-47,5$

\section{Versuch.}

1. $1 / 60$ Menschenserum (andere Probel)

2. Serum Kaninchen Nr. 8 wie im Vorversuch

3. Gemisch von 1 und 2, aia $10 \mathrm{ccm}: 1290$ ber.

4. Ueberstehende Flüssigkeit 912

5. Präzinitat, aus 3 und 4 berechnet . 378

6. Thorlösung in 0,85 proz. $\mathrm{NaCl}$. . 1820

7. Präzipitat, aufgelöst in dieser Thorsulfatlösung

8. Wert von 7 direkt beobachtet ' 2155

9 . Differenz von 7 und 8 . . $\quad-43$

Die beobachteten optischen Werte der spezifischen Immunpräzipitate betrugen somit $139,335,504$ und 421 Trommelteile, gaben also, absolut betrachtet, den mit Salzen von seltenen Erden erzielten nich viel nach, ja sie äbertrafen die Cer-Präzipitate sogar in zwei Fällen. In Prozenten der zur Reaktion gebrachten Eiweißmengen ausgedrückt würden sich allerdings die spezifischen Präzipitate niedriger stellen als bei den Kolloidmodellen, speziell im zweiten, dritten und vierten Versuch, wo sich die Serumkonzentration im Reaktionsgemisch wegen des erforderlichen Ueberschusses an präzipitierendem Kaninchenserum nicht auf $1: 40$, sondern etwa auf $1: 20$ bis $1: 15$ belief. Im übrigen glich die Immunpräzipitation außerordentlich dem Kolloidmodell, gleichgültig ob die Bestimmungen bald nach det Vermischung der beiden Sera oder melirere (bis 24 Stunden) später vorgenommen wurden. Die Differenzen zwischen dem errechneten und den (nach Wiederauflösung) beobachteten IW der Präzipitate schwankien zwischen 28 und 52 Trommeiteilen, waren als durchaus nicht größer als bei den Kolloidmodellen und hatten, was mir wichtig zu sein scheint, das gleiche Vorzeichen. d. h. der beobachtete Wert war stets etwas kleiner als der aus dem IW der überstehenden Flüssigkeit und dem erwartungsgemäßen arithmetischen Mittel der Reaktionskomponenten errechnete. Vermutlich liegt auch hier die Sache so, daß bei der Immunitätsreaktion der IW des Reaktionsgemisches selbst bei ausblèibender Flockung gleichfalls kleiner gefunden wird, ähnlich wie beim Kolloidmodell; Beobachtungen hierüber sollen nachgetragen werden.

Da bei den hier gewählten Kolloidmodellen bakterielle Verunreinigungen ebenso ausge- 
schlossen waren wie fermentative Prozesse, so darf der Parallelismus dieser Kolloidmodelle mit spezifischen Präzipitationsvorgängen wohl in dem Sinne interpretiert werden, daß auch für die letzteren ein enzymatischer Abbau des EiweiBantigens als Ursache der Eiweißlockung nicht notwendig in Betracht kommt. Damit soll nicht in Abrede gestellt werden, daB derartige Abbauprozesse ats sekundäre Erscheinungen $z$. B. bei langem Stehen eimes Reaktionsgemisches von EiweiBantigèn und Antiserum bei $37^{\circ} \mathrm{C}$ gelegentlich beobachtet werden können.

\section{Zus a menfassung.}

1. Die hier untersuchten Salze seltener Erden (Thorium, Cer, Praseodym, Lanthan) agglutinieren-Suspensionen von Zellen (roten Blutkörperchen, Bakterien, Schimmelpilzsporen) und geben mit EiweiBsolen Präzipitation (R. Mines). Das ist auch dann der Fall, wenn das Salz nicht kolloid, sondern wie ein typisches Kristalloid gelöst ist und wenn es in der Lösung nicht hydrolytisch dissozíiert wird.

2. Agglutination und Präzipitation treten noch bei sehr niedrigen Salzkonzentrationen auf (1 Tell Thoriumsulfat auf $5000-10000$ Teile Reaktionsgemisch). Vierwertige Kationen (Thorium) wirken stärker als dveiwertige (La, $\mathrm{Ce}, \mathrm{Pr}$ ); doch hängt die florkende Kraft nicht allein von der Wertigkeir, sondern auch von anderen noch unbekarnten Eigenschaften des Kations der seltenen Erde ab, sowie auch von der speziellen Beschaffenheit der flockbaren Eiweißkörper (verschiedene Agglutinabilität verschiedener Bakterieriarten durch das gleiche Salz ).

3. Die untersuchten Salze sind für pflanz. liches und tierisches Protoplasma toxisch. Die Giftigkeit wird anscheinend durch die Wertigkeit des Kations (Thor giftiger als Cer), durch seine sonstige Narur und durch die Empfindlichkeit der lebenden Zelle beeinfluBt; verschiedene Zellen sind verschieden empfindlich (Spirochaeten erwiesen sich als weit resistenter als Trypanosomen oder Typhusbazillen). Der Mechanismus der Vergiftung kann nicht auf einer einfactren Eiweißflockung beruhen; denn die EiweiBflockung ist im Ueberschuß von Eiweib reversibel (Punkt 6), die Vergiftung nicht (im Texte nicht zitierte Versuche mit Naganatrypanosomen).

4. Sporen von Bakterien und Schimmelpilzen werden wegen der Impermeabilität ihrer Membranen nicht angegrifien. Die leichte Agglutinierbarkeit dieser Formen deutet darauf hin, dab alle Arten von Zellagglutinationen Obcrflächenvorgänge darstellen.

5. Die Eiweibflockung durch Salze seltener Erden wird durch den relativen Uebergchutis ciner Reaktionskomponente gehemmt. Bei einem für die Flockung optimalen gegenseitigen Verhält nis von Eiweig und Salz existiert eine Konzentrationsschwelle (minimale Salzkonzentration). unterhalb welcher die Flockung ausbleibt. Diese Schwelle liegt für die Thorkationen wesentlich niedriger als für Cero-, Pr-oder gar La-lonen. ist also für die Jonen der seltenen Erden verschieden.

6. Die Flockung beruht auf der Entstehung lockerer Verbindungen von Eiweif und Salz (Thor-, Cer-Albuminaten) ähnlich wie bei den Eiweibflockungen durch Schwermetalle. Diese Verbindungen sind kolloidchemisch inaktiv und so wie die Verbindungen mit Schwermetallen (Gale otti) leicht reversibel; sie lösen sich rasch und vollständig im Ueberschusse einer Reaktionskomponente (Eiweibsol oder Salz der Erde). Hierbel können sich die verschiedenen Eiweibarten ebenso wie die Salze verschiedener Erden gegenseitig vertreten, wobei die lōsende (dispergierende) Wirkung der Erden-Katione der fällenden Kraft proportional ist. Thorsalze lösen also weit besser als Ceroverbindungen.

7. Die Analyse solcher Flockungen mit dem Lò w e'schen Interferometer ergibt, dak die ausflockenden Substanzmengen nicht nur von der relativen Konzentration, sondern auch vom Kation des Salzes abhängen; sie sind bei Thorflockungen dreimal so grob als selbst bei 20 fach gröberer Gewichtsmenge von fällendem Cerochlorid. Der Substanzverlust des Reaktionsgemisches findet sich (optisch bestimmt) nahezu quantitativ in dem durch Thorsulfat wieder dispergierten Präzipitat:

8. Die spezifische Präzipitation gleicht in vieler Hinsicht den Eiweifflockungen durch Thorund Cerosalze. Sie zeigt dieselbe Abhängigkeit der Niederschlagsbildung vom gegenseitigen Konzentrationsverhältnis der Reaktionskomponenten, wird durch relativen Ueberschul einer Komponente gehemimt ind ist durch die nämliche Reversibilität des' Reaktionsproduntes (Präzipitates) charakterisiert. Spezifische Präzipitate lösen sich ebenso wie die durch seltene Erden erzeugten Eiweißkoagele im Ueberschuß der Reaktionskomponenten, in $\mathrm{NaOH}$, in entsprechend konzentriertem Thorsulfat oder anderen Salzen seltener Erden, nicht aber in jedem beliebigen Eiweibsol. 
9. Interferometrisch zeigt die Immunpräzipitation dieselben Verhältnisse, wie sie in Punkt 7 für Thor- oder Cer-Flockungen angegeben wurden. Die absoluten Gröben und die Vorzeichen der Abweichungen zwischen beobachteten und errechneten IW der Niederschläge stimmen überein. Diese Sachlage macht die Annahme fermentativer Abbauprozesse des Eiweißantigens zur Erklärung der Immunpräzipitation überflüssig.

\section{Literatur.}

1. G. R. Mines, Kolloidchem. Beih. 3 (1912).

2. H. Ley, Zeitschr. f. physik. Chemie 30 (1899).
3. G. Galeotti, Hoppe-Seyler's Zeitschr. f. physik. Chemie 40 (1901).

4. P. Hirsch, Fermentforschung 2, Heft 4 (1919); 1 (1914); 2, Heft 3 (1918).

5. K. Lang en stra $\dot{B}$, Fermentforschung 3 , Heft 1 (1920)

6. P. Hirsch, Jenaische Zeitschr. f Naturw.56(1920).

7. A. Sim on ini, Zentralbl. f. Bakt. 74, I (1914).

8. Biltz, Much u. Siebert, E. v. Behring's Beitr. zur exp. Therapie, Heit 10.

9. Landsteiner u. Jagič, M. m. W. 1904.

10. Girard; Mangin, Henti, Compt. rend. 138 (1904).

11. Frou in und Ledebt, Compt. rend. Soc. Biol. 83, Nr. 5 (1920).

12. F ro u in u. Moussali, Compt. rend. Soc. Biol. 82 , Nr. 24 (1919)

\section{Untersuchungen über antagonistische Wirkungen zwischen lonen gleicher Ladung.) (Eingegangen am 6. Aupaus 1920.)}

Von S. M. Neuschlob.

(Aus dem plarmakologischen Institut der Universität Budapest.)

1. Einleitung.

Im folgenden sollen Untersuchungen dargestellt werden, welche sich auf antagonistische Wirkungen bei neutralen Elektroly: en bezietien.

Unter lonenantagonismus wird die $\mathrm{Er}$ scheinung verstanden, bei waicher die gleichgerichteten Einzelwirkungen $z$ weier gleichgeladener lonen sich gegenseitig aufheben oder zlmindest einschränken. Die Valenz der hierbei beteiligten Ionen ist im Prinzip nebensächlich. $\mathrm{Da}$ diese Untersuchungen eigentlich zur Deutung gewisser biologischer Erscheinungen unternommen worden sind, bei welchen den Kationen die ausschlaggebende Rolle zufällt, erstrecken sich dieselben lediglich auf die letzieren. $\mathrm{Ob}$. ähnliche Erscheinungen auch bei Verwendung verschiedener Anionen zutage treten, müssen weitere Untersuchungen entscheiden.

Erscheinungen, die unter den oben beschriebenen Begriff des lonerrantagonismas fallen würden, sind in der Literatur nur wenige erwähnt. $\mathrm{DaB}$ zwei ungleichwertige Kationen sich in ihrer fällenden Wirkung auf ein negatives

1) Det großte Teil dieser Untersuchungen, welche von biologischen Fragestellungen ausgehend unternommen worden sind, ist ausfihhrich in einer Reihe von Arbeiten in Pflüger's Archiv für die gesamte Physiologie 181 (1920) veröfientlicht worden. An dieser Stelle werden die Ergebnisse derselben, soweit sie auch für den Nichtbiologen von Intersse sein können, einer Aufforderung seitens det Schriftleitung der "Kolioid-Zeitschrift" entsprechend, nunmebr lediglich yon kolloidchemischen Gesichtspunkten aus dargestellt.
Arsensulfidsol nicht einfach additiv verhalten, während dies bei gleichwertigen Kationen der Fall ist, geht bereits aus einer Arbeit von Linder und Picton ${ }^{2}$ ) hervor. Ihre Versuche zeigten, daß, um eine vollkommene Fällung herbeizuführen, von dem einen Kation gröbere Mengen nötig sind, als - man unter der Voraussetzung einer Addition voraussetzen würde. Auch $\mathrm{Pauli}{ }^{3}$ ) meint bei seinen Studien über Elektrolytfällung an Eiweiß einen gewissen Grad von Antagonismus zwischen der Wirkung der Alkali- und Erdalkalisalze gefunden zu haben. $\mathrm{Ob}$ dies nun tatsächlich der Fall ist; läBt sich allerdings meines Erachtens bei der unübersichtlichen Art, auf welche $\mathrm{Pa}$ ali seine Versuchsergebnisse wiedergibt, schwer beurteilen. Dasselbe läbt sich auch von dem von Koch ${ }^{4}$ ) beobachteten Ionenantagonismus béi der Elektrolytfăllung von Lezithin sagen.

Neuerdings hat nun Le $\mathbf{k}^{5}$ ) eine gröBere Arbeit über die Bedeutung der Elektrolyte für Quellungsprqzesse " veröffentlicht, in welcher er sich auch eingehend mit den antagonistischen Ionenwirkungen beschäftigt. Er meint, in dem Vorgange, nach welchem Elektrolytgemische die Quellung einer Gelatinegallerte beeinflussen, lonenantagonismus nachgewiesen zu haben. Wenn wir aber seine Versuchs-

2) Linder u. Picton, Journ. chem. Soc. 67 (1895).

8) Wo. Pa uli, Hofmeister's Beitrage 3 (1903) und 5 (1904)

4) W. Koch, Zeitschr. f. physiol. Chem. 37 (1902).

b) E. Lenk, Biochem. Zeitschr. 72 (1916). 